\title{
Genetic variability for waxy genes in Argentinean bread wheat germplasm
}

\author{
Leonardo Sebastián Vanzetti \\ Grupo de Biotecnología y Recursos Genéticos \\ INTA EEA Marcos Juárez \\ Ruta 12 S/N, (2580) Marcos Juárez \\ Córdoba, Argentina \\ Tel: 543472425001 \\ Fax: 543472425001 \\ E-mail: lvanzetti@mjuarez.inta.gov.ar
}

\author{
Laura Alicia Pflüger \\ Instituto de Recursos Biológicos CIRN-INTA \\ INTA Castelar \\ Las Cabañas y Los Reseros, 1712 Castelar \\ Buenos Aires, Argentina \\ Tel: 54114621 1819/0840 \\ Fax: 54114621 1819/0840 \\ E-mail: lpfluger@cnia.inta.gov.ar
}

\section{Marta Rodríguez-Quijano}

Unidad de Genética

Departamento de Biotecnología

Escuela Técnica Superior de Ingenieros Agrónomos

Universidad Politécnica 28040

Madrid España

Tel: 34913365716

Fax: 34915434879

E-mail: mquijano@bit.etsia.upm.es

\section{José Maria Carrillo}

Unidad de Genética

Departamento de Biotecnología

Escuela Técnica Superior de Ingenieros Agrónomos

Universidad Politécnica 28040

Madrid España

Tel: 34913365716

Fax: 34915434879

E-mail: josem.carrillo@upm.es

\section{Marcelo Helguera*}

Grupo de Biotecnología y Recursos Genéticos

INTA EEA Marcos Juárez

Ruta 12 S/N, (2580) Marcos Juarez

Córdoba, Argentina

Tel: 543472425001

Fax: 543472425001

E-mail: mhelguera@mjuarez.inta.gov.ar

Financial support: Grant from the Government of Argentina, FONCyT - INTA PICTO 12948.

Keywords: characterization, molecular markers, Triticum aestivum L., starch, waxy genes, wheat.

Abbreviations: 1D: one dimensional

2D: two dimensional PCR: polymerase chain reaction

GBSS I: Granule Bound Starch Synthase I

MAS: marker assisted selection

SDS-PAGE: Sodium Dodecyl Sulfate-Polyacrylamide Gel Electrophoresis

SNPs: single nucleotide polymorphisms

*Corresponding author 
Amylose and amylopectin are the two polysaccharides that constitute starch in bread wheat and the enzyme GBSSI (Granule-bound starch synthase I), also known as waxy protein, is responsible for amylose synthesis in storage tissues. Decrease of the amylose content in starch has been associated with the lack of waxy protein(s). In this work, different sets of PCR markers were used to characterize the genetic variability of waxy loci from 103 Argentinean bread wheat cultivars. For the $W x-A 1$ locus, $W x-A 1 a$ and a novel molecular allele designed $W x-A 1 g$ were detected. $W x-B 1$ locus showed three alleles $(W x-B 1 a, W x-B 1 b, W x-B 1 e)$, and $W x-D 1$ locus showed only the $W x-D 1 a$ allele. Novel single-locus allele specific markers for $W x-A 1 b, W x-B 1 b$ and $W x-$ $D 1 b$ null alleles were also described. To our best knowledge this is the first study focused to characterize the genetic variability for waxy genes in bread wheat cultivars from South America.

Starch is a major component of wheat grain, accounting up to $65-70 \%$ of the dry matter in mature grain. Wheat starch is a polymer composed of two types of glucose carbohydrates: amylose, a lineal $\alpha-1,4$ glucan, and amylopectin, a lineal $\alpha-1,4$ glucan containing $\alpha-1,6$ branch points. The granule-bound starch synthases (GBSSI or waxy proteins), are the enzymes responsible for amylose synthesis in storage tissues (Yamamori et al. 1994). Because bread wheat (Triticum aestivum L.) is an allohexaploid species $(2 n=6 x=42$, genomic formula AABBDD) it has three different waxy proteins (Wx-A1, $W x-B 1, W x-D 1)$, encoded by three different genes: $W x-A 1$, $W x-B 1, W x-D 1$; located on chromosome arms 7AS, 4AL and 7DS, respectively (Nakamura et al. 1993a). Bread wheats with one or two non-functional (null) waxy genes produce starch with significant lower levels of amylose (partial waxy starch) (Nakamura et al. 1993b; Vrinten et al. 1999; Wickramasinghe and Miura, 2003). Partial waxy starch is a desirable trait in the development of wheat cultivars suitable for certain types of noodles (Epstein, 2002; Liu et al. 2003). Around the world several wheat collections have been characterized searching for null waxy proteins by $1 \mathrm{D}$ or 2D SDS-PAGE (Rodríguez-Quijano et al.

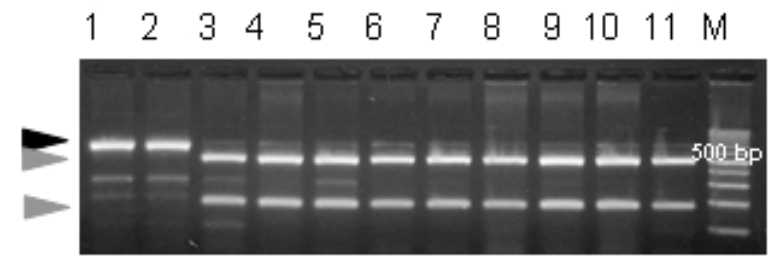

Figure 1. PCR products obtained using Wx-A1L/Wx-A1R primers after Hind III digestion. Lanes 1 to 11 are breeding lines/cultivars 1-DHWx12, 2-Komugi Norin, 3-Marinar, 4-Gamenya, 5-Baguette 10, 6-Buck Brasil, 7-Prointa Molinero, 8-Prointa Puntal, 9-Cronox, 10-Klein Martillo, 11-Prointa Granar, M: 100-pb ladder (Promega), 500-bp fragment is indicated. The black arrowhead indicates the 652-bp fragment from $W x-A 1 b$ allele, the grey arrowheads indicate 495-bp and 176-bp fragments from $W x-A 1 \mathrm{a}$ allele.

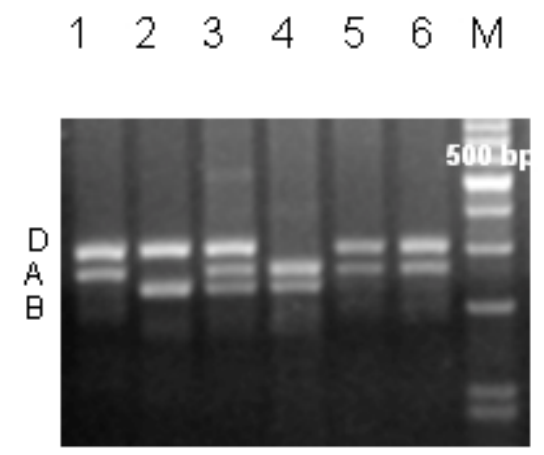

Figure 2a. PCR products obtained using \#4FI\#4R primers. Lanes 1 to 6 are breeding lines/cultivars 1-N4AT4B, 2N7AT7B, 3-N7BT7D, 4-N7DT7B, 5-Reeves, 6-Eradu and M: $100-\mathrm{pb}$ ladder (Promega), 500-bp fragment is indicated. Capital letters "D", "A" and "B" indicate PCR fragments from $W x-D 1 a, W x-A 1 a$ and $W x-B 1 a$ alleles.

1998; Demeke et al. 2000; Urbano et al. 2002) and PCR markers (Briney et al. 1998; Boggini et al. 2001; Nakamura et al. 2002; Urbano et al. 2002). In wheat, PCR markers can co-amplify two or three waxy genes simultaneously making difficult its use in marker-assisted selection (MAS); this is the case of PCR markers developed by Briney et al. (1998), McLauchlan et al. (2001), Nakamura et al. (2002), Urbano et al. (2002). Therefore, the development of single-locus allele specific markers for waxy null alleles is a desirable goal for MAS. In this study we report the development of single-locus allele specific markers for waxy nulls alleles suitable for MAS programs, and the characterization of the genetic variability of the $W x-A 1, W x-B 1$ and $W x-D 1$ loci in Argentinean bread wheat cultivars using molecular markers as a tool.

\section{MATERIALS AND METHODS}

\section{Plant materials}

A set of 103 bread wheat cultivars (T. aestivum L.) from Argentina (Table 1) was screened using a set of molecular markers to assess the frequency of different $W x-A 1, W x-B 1$ and $W x-D 1$ alleles. Seed stocks were obtained from INTA Marcos Juárez and/or INTA Castelar Wheat Germplasm Collections (Argentina). Australian wheat cultivars Bodallin, Cadoux, Eradu, Gamenya, Halberd and Reeves were used as controls carrying $W x-B 1 b$ allele (Briney et al. 1998).The Spanish wheat landrace Mariñar (accession BG018258) was used as control carrying $W x$-B1e allele (Rodríguez-Quijano et al. 1998). The Chinese wheat cultivar Komugi Norin was used as control carrying $W x-$ $A 1 b$ allele and the Australian breeding line DHWx12 was used as triple-null control ( $W x-A 1 b / W x-B 1 b / W x-D 1 b)$ (Shariflou and Sharp, 1999). Nullitetrasomic lines of cv. Chinese Spring, N7AT7B, N4AT4B, N7BT7D and N7DT7B were used to validate the genome specificity of the designed primers. 


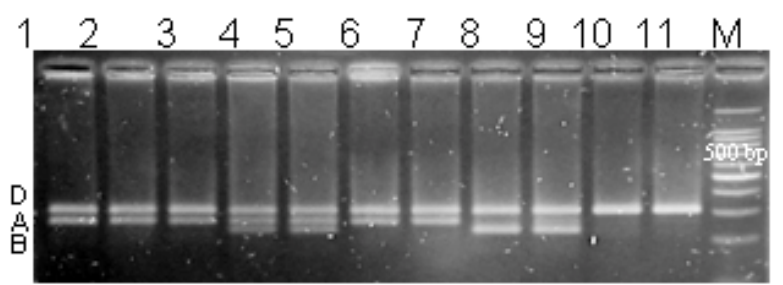

Figure 2b. PCR products obtained using \#4F/\#4R primers. Lanes 1 to 11 are breeding lines/cultivars 1-Gamenya, 2DHWx12, 3-Mariñar, 4-Baguette 10, 5-Buck Brasil, 6-Prointa Molinero, 7-Prointa Puntal, 8-Cronox, 9-Klein Martillo, 10-Prointa Granar, 11-ACA 801 and M: 100-pb ladder (Promega), 500-bp fragment is indicated. Capital letters "D", "A" and "B" indicate PCR fragments from $W x-D 1 a, W x-A 1 a$ and $W x-B 1 a$ alleles.

\section{DNA extraction, primer design, PCR reactions and sequencing}

Genomic DNA from leaves of single plants was isolated as described before (Weining and Langridge, 1991). Different primer combinations based on previously published sequences were used to amplify preferentially different alleles from $W x-A 1, W x-B 1$ and $W x-D 1$ genes (Murai et al. 1999; Vrinten et al. 1999). Details about primer sequences, amplified loci and cycling conditions are in Table 2 . PRIMER3 program (Rozen and Skaletsky, 2000) was used for primer design. Primers \#4F/\#4R were developed by McLauchlan et al. (2001). The PCR reactions were performed in a MJ Research thermocycler model PTC 100 in a $25 \mu \mathrm{l}$ reaction mixture. Each reaction consisted of $1 \mathrm{X}$ Taq polymerase buffer (Promega Corp. Madison WI), 1.0 U Taq DNA polymerase (Promega), $200 \mu \mathrm{M}$ of each dNTP (Promega), $0.2 \mu \mathrm{M}$ of each primer, and 100-150 ng of wheat genomic DNA as template, Magnesium Chloride concentrations are detailed in Table 2. Following amplification with primers Wx-A1L/Wx-A1R, $10 \mu \mathrm{l}$ of PCR products were directly digested with restriction enzymes Hind III (New England Biolabs Inc. Beverly MA), by adding 5 units of enzyme to the PCR products and incubating for $90 \mathrm{~min}$ at $37^{\circ} \mathrm{C}$. Direct PCR fragments and digested products were separated by electrophoresis on $2 \%$ agarose gels in 1X SB Buffer (Brody and Kern, 2004), stained with Ethidium bromide [0.5 g/L] and visualized by UV exposure. DNA sequencing was performed directly from PCR fragments purified using Wizard SV Gel and PCR clean-Up System Kit (Promega) using the amplification primers in both directions. Detected mutations were confirmed by sequencing of PCR fragments from at least two independent PCR reactions.

\section{Waxy protein extraction and electrophoresis}

In a subset of 53 bread wheat cultivars (underlined in Table 1) starch granule-bound proteins (including waxy protein) were extracted from embryoless grains, and later separated by SDS-PAGE as described by Rodríguez-Quijano et al. (1998). Protein patterns were visualized by silver stain using the Silver Express kit (Invitrogen Corp. Carlsbad CA).

\section{RESULTS}

\section{Wx-A1 locus}

Three sets of PCR primers considering proximal and central portions of $W x-A 1$ gene were used. Primers $\mathrm{Wx}-\mathrm{A} 1 \mathrm{~F} / \mathrm{Wx}-$ A1R amplify a 671-bp fragment from the proximal region of the $W x-A 1$ locus in plants carrying the $W x-A 1 a$ allele and a 652-bp fragment in plants with the $W x-A 1 b$ allele described by Vrinten et al. (1999). The amplification products from $W x-A 1 a$ (671-bp) and $W x-A 1 b$ (652-bp) alleles can not be easily separated in agarose gels, therefore, we found a polymorphic Hind III restriction site in the sequence from the $W x-A 1 a$ allele that divides the 671-bp fragment into two fragments of 495-bp and 176-bp (Figure 1, lanes 4 to 11), this restriction site is not present into the $W x$-A1b sequence (Figure 1, lanes 1 and 2). The described markers are an effective tool to select $W x-A 1 b$ allele in marker-assisted selection breeding. When primers Wx-A1F/Wx-A1R were used to evaluate the genetic variability in the selected 103 Argentinean bread wheats, all the samples showed the $W x-A 1 a$ allele.

Primers \#4F/\#4R were initially designed to detect the null $W x$-B1b allele (McLauchlan et al. 2001). These primers coamplify exons 5 and 6 of the three homoeoalleles of $W x-A 1$, $W x-B 1$ and $W x-D 1$ genes and were used to detect genetic variability in this portion of the $W x-A 1$ locus. In Figure 2a, the larger fragment (299-bp) belongs to the D genome, the intermediate (257-bp) to the A genome and the smaller one (227-bp) to the B genome. When this marker was used to evaluate the genetic variability in Argentinean germplasm, 78 cultivars (76\%) showed the 257-bp fragment associated with the $W x$-A1 locus ( $W x$-A1a allele) (Figure $2 b$ lines 4,5 , 6 and 7), and 25 (24\%) showed absence of the 257-bp fragment (Figure 2b lines 8, 9, 10 and 11), which is an unexpected high proportion of putative $W x$ - $A 1$ null alleles. We also found that DHWx12 (Wx-A1b control) amplified

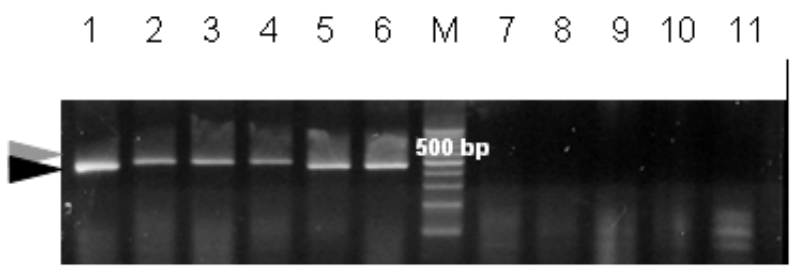

Figure 3. PCR amplification products obtained using $\mathbf{W x}-$ B1F/WX-B1R primers. Lanes 1 to 11 are breeding lines/cultivars 1-Biointa 3000, 2-Mariñar, 3-Buck. Pingo, 4-Buck Poncho, 5-Triguero 100, 6-Prointa Bon. Hurón, 7-Prointa. Milenium, 8-Prointa Granar, 9-Gamenya, 10-Cadoux, 11$\mathrm{DHW} \times 12$ and lane $\mathrm{M}$ is a DNA size standard (100-bp ladder, Biodynamics Corp.). The black arrowhead indicates the 461-bp fragment from $W x-B 1 a$ allele, the grey arrowhead indicate 495 $\mathrm{bp}$ fragment from $W x-B 1 e$ allele and lack of amplification is $W x-$ $B 1 b$ allele. 


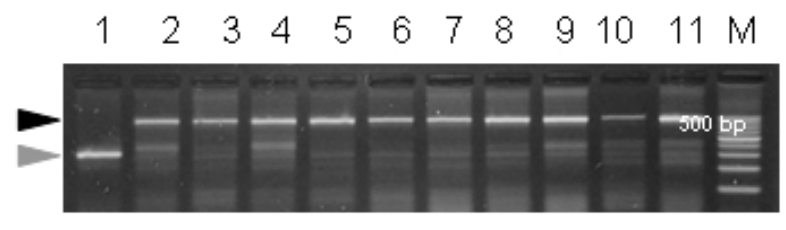

Figure 4. PCR amplification products obtained using WxD1L/Wx-D1R primers. Lanes 1 to 11 are breeding lines/cultivars 1-DHWx12, 2-Buck Arriero, 3-Biointa 2001, 4Klein Gavilán, 5-Baguette 10, 6-Buck Brasil, 7-Prointa Molinero, 8-Prointa Puntal, 9-Cronox, 10-Klein Martillo, 11Prointa Granar, and lane M: 100-pb ladder (Promega), 500-bp fragment is indicated. The black arrowhead indicates the 930bp fragment from $W x-D 1 a$ allele and the grey arrowhead indicates the 342-bp fragment from $W x-D 1 b$ allele.

the 257-bp fragment of the $W x-A 1 a$ allele (Figure $2 b$ lane 2).

To confirm that result, local cultivars were tested with a third set of primers $W x-A 1$-specific that included \#4F/\#4R primers region (Wx-A2L/Wx-A2R), and surprisingly, all of them amplified a 491-bp fragment. The specificity of WxA2L/Wx-A2R primers for $W x-A 1$ locus was confirmed by the lack of amplification of the 491-bp fragment in N7AT4B Chinese Spring nullitetrasomic line. Sequence comparison of PCR products amplified with Wx-A2L/WxA2R primers from local cultivars previously scored as "nulls" for $W x-A 1$ locus using \#4F/\#4R primers, showed two silent single nucleotide polymorphisms (SNPs), one of them located in the annealing site of the primer \#4R (Figure 5). The primer \#4R has an additional mismatch at position 17 (starting from the 3 ' end), as \#4F/\#4R primers amplify simultaneously $W x-A 1, W x-B 1$ and $W x-D 1$ genes, these two mismatches (one in the $W x-A 1 g$ sequence, one in the \#4R primer) would favour $W x-B 1$ and $W x-D 1$ amplification against $W x-A 1 g$. This is not a real "null" allele, so we propose to designate it as $W x-A 1 g$ (GeneBank accession DQ431232).

\section{Wx-B1 locus}

When using \#4F/\#4R primers, 81 tested cultivars (79\%) showed the 227-bp PCR fragment for the $W x$-B1a allele (Figure 2b lanes 4, 5, 8 and 9) and 22 (22\%) showed absence to the 227-bp PCR fragment ( $W x-B 1 b$ allele, Figure 2b lanes 6, 7, 10 and 11). Wheat cultivars Gamenya, Cadoux, Reeves and Bodallin ( $W x-B 1 b$ controls), and unexpectedly, the landrace Mariñar (control $W x-B 1 e$, Rodríguez-Quijano et al. 1998) (Figure 2b lane 3) showed absence to the 227-bp PCR fragment.

To confirm that result a second combination of $W x-B 1$ specific primers (Wx-B1L/Wx-B1R) was included in the analysis. This marker amplifies a 461-bp fragment in bread wheats with $W x-B 1 a$ allele and no PCR fragments are observed in wheats carrying $W x-B 1 b$ allele (nulls). With this marker, 81 of 103 cultivars (78\%) showed the 461-bp PCR fragment and were scored as $W x-B 1 a$ as before (Figure 3 lanes 1, 5 and 6), but only 17 cultivars (16\%) showed absence of the 461-bp fragment and were scored as $W x$-B1b (Figure 3 lanes 7 and 8 ). The 5 remaining cultivars (5\%), including the control $W x-B 1 e$ landrace Mariñar, amplified a slightly larger fragment 495-bp long (Figure 3 lanes 2, 3 and 4).

The 495-bp PCR fragment was amplified from the local cultivar Buck Poncho and sequenced (GeneBank AY954026). Sequence comparison of that fragment and the $W x-B 1 a$ allele showed nine SNPs in intron 5; six SNPs in exons 5 and 6, including four silent mutations and two amino acid changes in exon 5 (Ser to Asn and Arg to Met) and a 34-bp insertion in intron 5 that explain the different size (Figure 6). In addition, SDS-PAGE analysis in cultivars carrying Buck Poncho allele showed a $W x$-B1 protein that migrate slightly slower than $W x-B 1 a$, having the same size of the $W x$-B1e allele in Mariñar (Figure 7). Therefore, PCR fragment size and waxy protein band size were used as arguments to assign the 495-bp PCR fragment amplified with primers $\mathrm{Wx}-\mathrm{B} 1 \mathrm{~L} / \mathrm{Wx}-\mathrm{B} 1 \mathrm{R}$ from the local

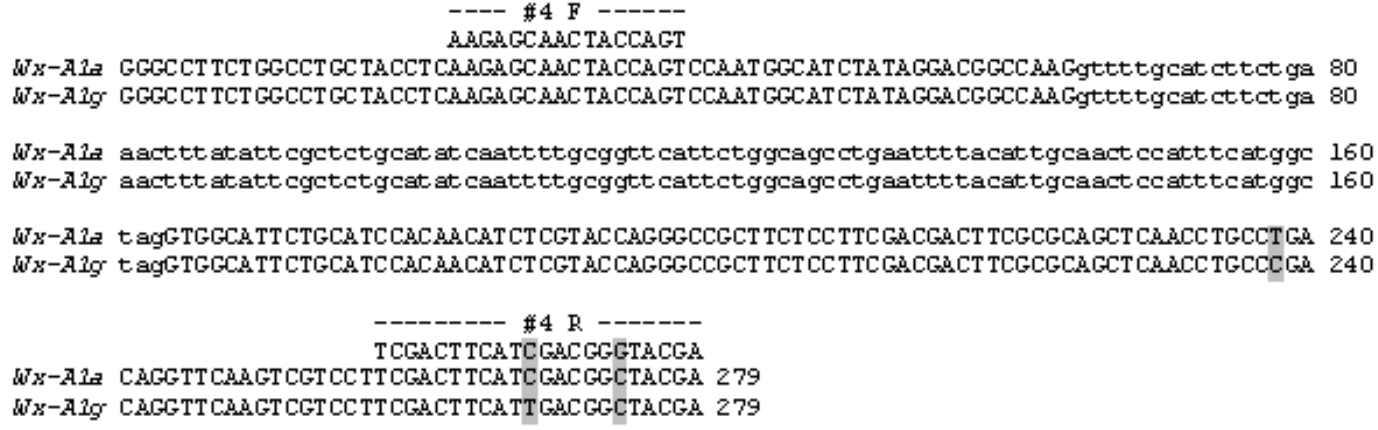

Figure 5. Best-fit alignment of partial nucleotide sequences (middle region of the $W x-A 1$ gene) including $W x-A 1 a$ (AB019622) and $W x-A 1 g$ (DQ431232) alleles from bread wheat. Mismatches are gray-shaded, and exons 5 and 6 regions are in capitals. Locations of \#4 F and \#4 R primers are also indicated. 


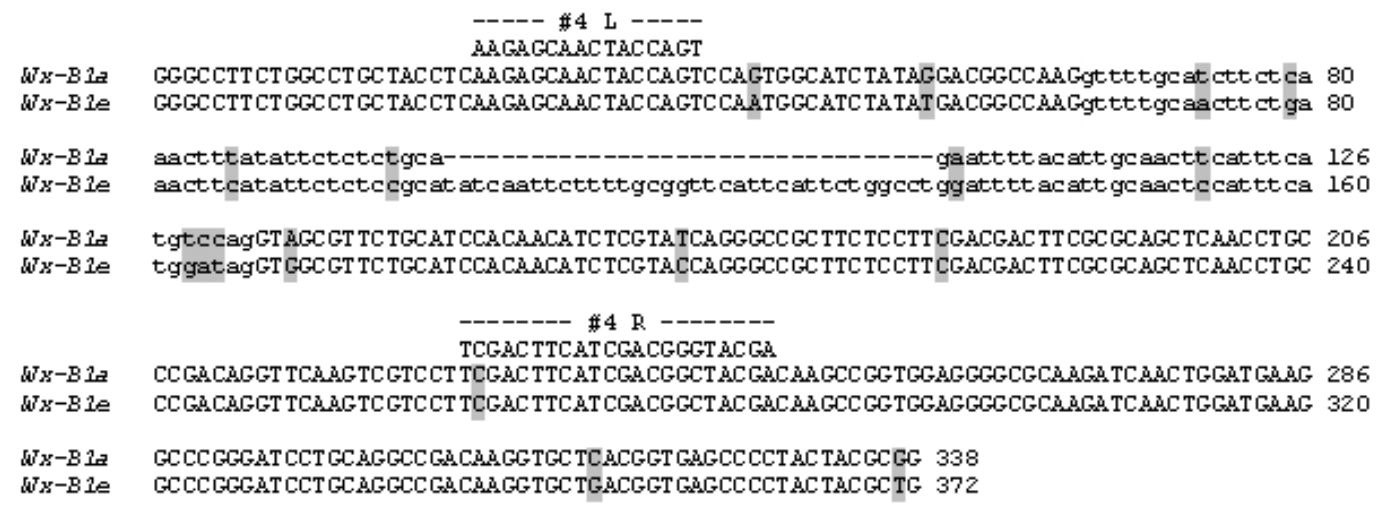

Figure 6. Best-fit alignment of partial nucleotide sequences (middle region of the $W x-B 1$ gene) including $W x-B 1 a$ and $W x-B 1 e$ alleles from bread wheat (GenBank accessions AB019623 and AY954026). Gaps were introduced to maximize nucleotide alignment and are indicated with dashes, mismatches are gray-shaded, exons are in capital. Annealing sites of \#4 L and \#4 R primers (McLauchlan et al. 2001) are also indicated.

cultivar Buck Poncho to the $W x$-B1e allele.

\section{Wx-D1 locus}

For the molecular characterization of the $W x-D 1$ locus two set of primers were used. The set of primers Wx-D1L/WxD1R was developed to detect the $W x$-D1b allele described by Vrinten et al. (1999) in the cultivar Bai Huo. These primers amplified a 930-bp fragment from the distal region of the wild type $W x-D 1 a$ allele and also included a 588-bp deletion present in the $W x-D 1 b$ allele. The $W x-D 1 b$ control breeding line DHWx12 showed the mutation described by Vrinten et al. (1999) in Bai Huo (Figure 4 lane 1). When this molecular marker was used to evaluate the genetic variability in 103 Argentinean bread wheat cultivars, all tested samples showed the $W x-D 1 a$ allele. (Figure 4 lanes 2 to 11$)$.

Primers \#4F/\#4R were also used to characterize the genetic variability of the $W x-D 1$ locus and no molecular variability was detected. SDS-PAGE protein analysis showed the GBSSI subunit corresponding to the $W x$ - $D 1$ locus in all tested cultivars, confirming previous data observed with PCR markers (data not shown). The lack of variability observed in the $W x$-D1 locus in comparison with $W x-A 1$ and $W x-B 1$ loci agreed with previous data (Graybosh et al. 1998).

\section{DISCUSSION}

Urbano et al. (2002) expressed that waxy protein polymorphism in wheat is not very high, especially when compared with other group of proteins, such as storage proteins of wheat kernels. A possible explanation could be that most of the initial characterization studies of waxy proteins in wheat were performed by SDS PAGE of GBSSI proteins from starch granules, and with this technology small differences between proteins might be underestimated. In this context, molecular markers can be a valuable tool to characterize the genetic variability of waxy genes at DNA level, as sequences from $W x-A 1, W x-B 1, W x-$ $D 1$ genes are available (Murai et al. 1999). Moreover, the polyploid nature of bread wheat and the high homology between $\mathrm{A}, \mathrm{B}$ and $\mathrm{D}$ genomes, are difficult issues to overcome in the development of single-locus allele specific markers because of the always latent possibility of coamplifying homologous alleles. This is the case of markers for waxy genes developed by Briney et al. (1998), McLauchlan et al. (2001), Nakamura et al. (2002) and Urbano et al. (2002).

In this work we used allele-specific mutations to develop single-locus allele specific markers for $W x-A 1, W x-B 1, W x-$ $D 1$ genes. As expected, the most frequent alleles in waxy

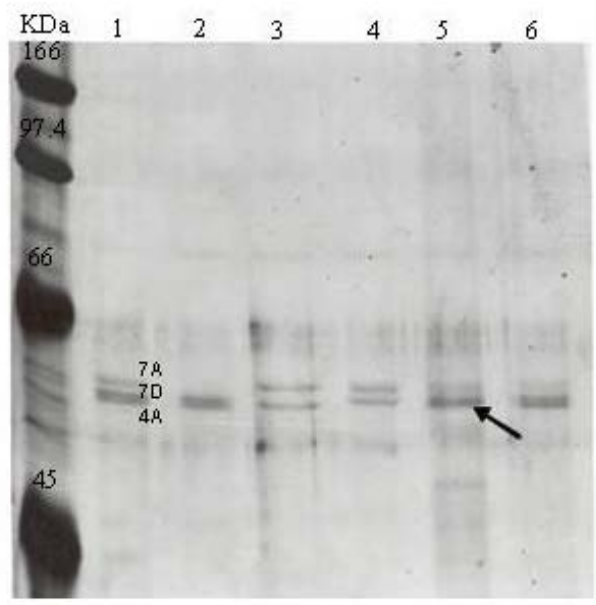

Figure 7. SDS-PAGE of waxy proteins from bread wheat. Lanes 1 to 6 are: 1-Chinese Spring, 2-N7AT7B, 3-N7DT7B, 4N4AT4B, 5-BuckPoncho (Wx-A1a, Wx-D1a, Wx-B1e) and 6Buck Arriero $(W x-A 1 a, W x-D 1 a, W x-B 1 a)$. The arrow (lane 5) indicate the $W x-B 1 e$ allele. The chromosomal locations of the isoproteins are indicated. Protein size standards are included in the left (lane M). 
Table 1. Genetic variability of $W x-A 1, W x-B 1$ and $W x-D 1$ loci in Argentinean bread wheat cultivars obtained using PCR markers. In underlined, cultivars in which waxy proteins were also characterized by SDS-PAGE.

\begin{tabular}{|c|c|c|c|}
\hline & an & & Cultivar Name \\
\hline a & a & $a$ & $\begin{array}{l}\text { Acienda, Baguette 10, Baguette 19, Baguette 20, Baguette Premium 13, } \\
\text { Biointa } 3000, \text { Biointa } 3003 \text {, Bonaerense Cauquén, Bonaerense Pasuco, } \\
\text { Bordenave Puán Sag., Buck Arriero, Buck Brasil, Buck Chacarero, Buck } \\
\text { Chambergo, Buck Charrúa, Buck Farol, Buck Guapo, Buck Guatimozín, Buck } \\
\text { Manantial, Buck Mataco, Buck Mejorpan, Buck Namuncurá, Buck Nandú, } \\
\text { Buck Palenque, Buck Pampero, Buck Panadero, Buck Patacón, Buck } \\
\text { Sureño, Buck Yapeyú, Buck Yatasto, Caudillo, Cooperación Liquen, } \\
\text { Cooperación Millán, Cooperación Nahuel, Diamante INTA, Furlani Accidio, } \\
\text { General Roca INTA, Inia Churrinche, Inia Condor, Inia Tijetera, Inia Torcaza, } \\
\text { Klein Cobre, Klein Don Enrique, Klein Escudo, Klein Flecha, Klein Gavilán, } \\
\text { Klein Jabalí, Klein Proteo, Klein Tauro, Leones INTA, Lona, Malambo, } \\
\text { Marcos Juárez INTA, Pergamino Gaboto, Prointa Bon. Hurón, Prointa Bon. } \\
\text { Redomón, Prointa Cauquén, Prointa Colibrí, Prointa Elite, Prointa Gaucho, } \\
\text { Prointa Guazú, Prointa Hurón, Prointa Imperial, Prointa Oasis, Prointa Súper, } \\
\text { Triguero 100 }\end{array}$ \\
\hline a & $b$ & a & $\begin{array}{l}\text { Buck Mataco, Granero INTA, Klein Chajá, Klein Escorpión, Klein Rendidor, } \\
\text { Prointa Molinero, Prointa Puntal }\end{array}$ \\
\hline a & e & a & $\underline{\text { ACA 302, ACA 303, Biointa 2001, Buck Pingo, Buck Poncho }}$ \\
\hline g & a & a & $\begin{array}{l}\text { ACA 223, Buck Biguá, Buck Pronto, Cronox, Greina, Klein Martillo, Klein } \\
\text { Pegaso, Klein Salado, Klein Volcán, Las Rosas INTA, Pampa INTA, Prointa } \\
\underline{5 \text { Cerros, Prointa Bon. Alazán, Prointa Huen Pan, Zorzal }}\end{array}$ \\
\hline$g$ & $b$ & $a$ & $\begin{array}{l}\text { ACA } 801, \text { Agrovic } 2000 \text {, Buck Guaraní, Cooperación Nahuel, Klein Sagitario, } \\
\text { Prointa Amanecer, Prointa Don Humberto, Prointa Federal, Prointa Granar, } \\
\text { Prointa Milenium }\end{array}$ \\
\hline
\end{tabular}

genes from tested wheat cultivars were the wild types (Table 1). Moreover, additional genetic variability in $W x-$ $A 1$ and $W x-B 1$ loci was detected.

$W x-A 1 g$ is a new allele whose origin is probably CIMMYT, as the most ancient reference stocks in this work are Pampa INTA and Las Rosas INTA (year of release 1984) which are selections from CIMMYT germplasm and Klein Salado (year of release 1985) which is a selection from local and CIMMYT germplasm. As previously expressed, mutations associated with changes in aminoacid composition were not detected in partial $W x-A 1 g$ sequence, suggesting that protein function has not been affected in this allele. In line with these arguments, waxy protein patterns in cultivars scored as $W x-A 1 a$ and $W x-A 1 g$ were identical, different from $W x-A 1 c$ allele with a slightly altered isoelectric point and from $W x-A 1 b$ and $W x-A 1 f$ which showed real null protein alleles (Yamamori et al. 1994; Saito et al. 2004). $W x$-A1d and $e$ alleles were described in the bread wheat relatives $T$. dicoccoides $(W x-A 1 d)$ and $T$. durum $(W x-A 1 e)$, respectively (Yamamori et al. 1995) as protein bands with sizes different from $W x-A 1 a$, which is not the case of $W x$ A1g.

The origin of $W x-B 1 b$ allele in local germplasm is also unclear, as it was detected in cultivars developed using CIMMYT germplasm (Prointa Puntal, Klein Escorpión, Klein Chajá) and old local germplasm (Klein Rendidor, year of release 1954). The cultivars scored in this study as $W x-B 1 b$ showed lack of PCR products with two different sets of primers (\#4F/\#4R, Wx-B1L/Wx-B1R) and lack of the diagnostic $W x-B 1 a$ protein fragment by SDS-PAGE. This data suggest the presence of a large mutation similar to the null $W x-B 1 b$ allele described by Vrinten et al. (1999) in the cultivar Kanto 107. This mutation is the most frequent null mutation for waxy genes in wheat, having been detected in germplasm from Asia, Europe and North America (Saito et al. 2004) but not from South America, being this study the first report. Unfortunately the extend of the $W x-B 1 b$ deletion has not been established yet; therefore, it is uncertain if the size of the putative deletion observed in local cultivars carrying $W x-B 1 b$ allele is the 
Table 2. Primer names, sequences, amplified loci and cycling conditions.

\begin{tabular}{|c|c|c|c|}
\hline Name & Sequence & Amplified loci & Cycling Conditions \\
\hline Wx-A1L & CCCCAAAGCAAAGCAGGAAAC & \multirow{2}{*}{ Wx-A1 } & \multirow{2}{*}{$\begin{array}{l}39 \text { cycles of } 94^{\circ} \mathrm{C} 45 \mathrm{sec}, 55^{\circ} \mathrm{C} 30 \mathrm{sec}, 72^{\circ} \mathrm{C} \\
1 \mathrm{~min} .\end{array}$} \\
\hline Wx-A1R & CGGCGTCGGGTCCATAGATC & & \\
\hline Wx-A2L & CGCAGGGGAAGACGTGGT & \multirow{2}{*}{ Wx-A1 } & \multirow{2}{*}{$\begin{array}{l}39 \text { cycles of } 94^{\circ} \mathrm{C} 45 \mathrm{sec}, 65^{\circ} \mathrm{C} 40 \mathrm{sec}, 72^{\circ} \mathrm{C} \\
50 \mathrm{sec} .\end{array}$} \\
\hline Wx-A2R & CGTTGACGATGCCGGTGATC & & \\
\hline Wx-B1L & CGCAGGGGAAGACGTGGT & \multirow{2}{*}{ Wx-B1 } & \multirow{2}{*}{$\begin{array}{l}39 \text { cycles of } 94^{\circ} \mathrm{C} 45 \mathrm{sec}, 65^{\circ} \mathrm{C} 40 \mathrm{sec}, 72^{\circ} \mathrm{C} \\
50 \mathrm{sec}\end{array}$} \\
\hline Wx-B1R & CGTTGACGATGCCGGTGATG & & \\
\hline Wx-D1L & GCCGACGTGAAGAAGGTGGTG & \multirow{2}{*}{ Wx-D1 } & \multirow{2}{*}{$\begin{array}{l}39 \text { cycles of } 94^{\circ} \mathrm{C} 45 \mathrm{sec}, 55^{\circ} \mathrm{C} 30 \mathrm{sec}, 72^{\circ} \mathrm{C} \\
1 \mathrm{~min} .\end{array}$} \\
\hline Wx-D1R & CCCCTTGCGTCATTTGTTGTGT & & \\
\hline$\# 4 \mathrm{~F}$ * & AAGAGCAACTACCAGT & \multirow{2}{*}{$\begin{array}{l}W x-A 1, W x-B 1 \text { and } \\
W x-D 1\end{array}$} & \multirow{2}{*}{$\begin{array}{l}\text { (1) Touch down step of } 94^{\circ} \mathrm{C} 1 \mathrm{~min}, 64^{\circ} \mathrm{C} \text { to } \\
58^{\circ} \mathrm{C}\left(-1^{\circ} \mathrm{C} / 2 \text { cycles }\right) 1 \mathrm{~min}, 72^{\circ} \mathrm{C} 1 \mathrm{~min} \text {. (2) } \\
35 \mathrm{cycles} \text { of } 94^{\circ} \mathrm{C} 1 \mathrm{~min}, 58^{\circ} \mathrm{C} 1 \mathrm{~min}, 72^{\circ} \mathrm{C} \\
30 \text { sec. }\end{array}$} \\
\hline$\# 4 R^{*}$ & TCGTACCCGTCGATGAAGTCGA & & \\
\hline
\end{tabular}

* $\left[\mathrm{MgCl}_{2}\right] 3 \mathrm{mM}$. Other primer combinations $\left[\mathrm{MgCl}_{2}\right] 1.5 \mathrm{mM}$.

same that the $W x-B 1 b$ allele described by Vrinten et al. (1999) in the cultivar Kanto 107. Further fine mapping studies focused on $W x B 1 b$ allele can answer this question.

In the case of the $W x$-B1e allele, the most probable origin is Buck Poncho, a selection from local germplasm released in 1986, because all the other cultivars carrying $W x$-B1e allele share Buck Poncho in their pedigree. The $W x-B 1 e$ allele is difficult to detect with markers \#4L/\#4R developed by McLauchlan et al. (2001) and by GBSS pattern detection in SDS-PAGE because of fragment overlapping. Cultivars with the $W x$-B1e allele using \#4L/\#4R primers will generate fragments of 261-bp, which is very close to the 257-bp of $W x-A 1 a$ allele, and they will be probably scored as "nulls" for $W x-B 1$ locus in agarose gels. The $W x$-B1e allele is also difficult to be detected by SDS-PAGE because its mobility is similar to the $W x-D 1 a$ allele (lower mobility than $W x$ B1a) (Demeke et al. 2000; Marcoz-Ragot et al. 2000; Yamamori and Quynh, 2000). In this work we describe a novel single-locus allele specific marker that accurately detects the $W x$-B1e allele in agarose gels. This marker is a valuable tool to develop isogenic lines for $W x$-B1e allele to evaluate the effect of amino acid changes detected in exon 5 of the $W x$-B1e allele in amylose/amylopectin ratio.

The importance of the identification of new forms of waxy protein is related to a reduction in the amylose content found in genotypes carrying these mutations (null mutations) (Nakamura et al. 1993b). In this work we have detected one allele $(W x-B 1 b)$ with a deleterious effect in protein function, and a second allele $(W x-B 1 e)$ carrying several mutations whose effect in protein function still have to be elucidated. The $W x-B 1 b$ allele was detected in $16 \%$ of wheat cultivars. These cultivars carrying partial waxy starch can be an attractive target in the development of local adapted cultivars, suitable for certain specialties like dry white chinese noodles (Liu et al. 2003). No null alleles for $W x-A 1$ or $W x-D 1$ loci were detected in our bread wheat collection, which agree with data observed in European germplasm (Marcoz-Ragot et al. 2000). The vast majority of germplasm carrying $W x-A 1 b$ or $W x-D 1 b$ alleles is from Turkey, Korea, Japan (Yamamori et al. 1994) and probably, China. The molecular markers single-loci allele specific for nulls $W x-A 1 b$, and $W x-D 1 b$ alleles are being used to introgress foreign null $W x-A 1 b$ and $W x-D 1 b$ alleles in local germplasm by marker assisted selection programs in order to develop adapted wheats with partial and total waxy starchs with different levels of amylose content.

\section{ACKNOWLEDGMENTS}

L. Vanzetti expresses his gratitude to FONCYT-INTA for a PICTO fellowship during this work which is part of his $\mathrm{PhD}$ Thesis. The authors want to express their gratitude to Paola Romina Aurelia for her excellent technical assistance, to Beatriz Formica for providing the wheat seeds used in this study and to Jorge Dubcovsky for his valuable suggestions in the writing of this paper. 


\section{REFERENCES}

BRINEY, A.; WILSON, R.; POTTER, R.H.; BARCLAY, I.; CROSBIE, G.; APPELS, R. and JONES, M.G.K. A PCR-based marker for selection of starch and potential noodle quality in wheat. Molecular Breeding, October 1998, vol. 4, no. 5, p. 427-433.

BRODY, J.R. and KERN, S.E. Sodium boric acid: A Trisfree, cooler conductive medium for DNA electrophoresis. BioTechniques, February 2004, vol. 36, no. 2, p. 214-216.

BOGGINI, G.; CATTANEO, M.; PAGANONI, C. and VACCINO, P. Genetic variation for waxy proteins and starch properties in Italian wheat germplasm. Euphytica, May 2001, vol. 119, no. 1-2, p. 113-116.

DEMEKE, T.; HUCL, P. and CHIBBAR, R.N. Frequent absence of GBSS $1 \mathrm{~B}$ isoprotein in endosperm starch of Canadian wheat cultivars. Starch, October 2000, vol. 52, no. 10, p. 349-352.

EPSTEIN, J.; MORRIS, C.F. and HUBER, K.C. Instrumental texture of white salted noodles prepared from recombinant inbred lines of wheat differing in the three granule bound starch synthase (Waxy) genes. Journal of Cereal Science, January 2002, vol. 35, no. 1, p. 51-63.

GRAYBOSCH, R.A.; PETERSON, C.J.; HANSEN, L.E.; RAHMAN, S.; HILL, A. and SKERRITT, J.H. Identification and characterization of US wheats carrying null alleles at the $W x$ loci. Cereal Chemistry, January 1998, vol. 75, no. 1, p. 51-54.

LIU, J.; HE, Z.; YANG, J.; XU, Z.; LIU, A. and ZHAO, Z. Variation of starch property and its relationship with dry white Chinese noodle quality in common wheat. Agricultural Science in China, February 2003, vol. 36, no. 2, p. 1-7.

MARCOZ-RAGOT, C.; GATEAU, I.; KOENIG, J.; DELAIRE, V. and BRANLARD, G. Allelic variants of granule-bound starch synthase proteins in European bread wheat varieties. Plant Breeding, August 2000, vol. 119, no. 4, p. 305-309.

MCLAUCHLAN, A.; OGBONNAYA, F.C.; HOLLINGSWORTH, B.; CARTER, M.; GALE, K.R.; HENRY, R.J.; HOLTON, T.A.; MORELL, M.K.; RAMPLING, L.R.; SHARP, P.J.; SHARIFLOU, M.R.; JONES, M.G.K. and APPELS, R. Development of robust PCR-based DNA markers for each homoeo-allele of granule-bound starch synthase and their application in wheat breeding programs. Australian Journal of Agriculture Research, 2001, vol. 52, no. 11-12, p. 14091416.

MURAI, J.; TAIRA, T. and OHTA, D. Isolation and characterization of the three Waxy genes encoding the granule-bound starch synthase in hexaploid wheat. Gene, June 1999, vol. 234, no. 1, p. 71-79.

NAKAMURA, T.; VRINTEN, P.; SAITO, M. and KONDA, M. Rapid classification of partial waxy wheats using PCR-based markers. Genome, December 2002, vol. 45, no. 6, p. 1150-1156.

NAKAMURA, T.; YAMAMORI, M.; HIRANO, H. and HIDAKA, S. Identification of three $\mathrm{Wx}$ proteins in wheat (Triticum aestivum L.). Biochemical Genetic, 1993a, vol. 31, no. 1-2, p. 75-86.

NAKAMURA, T.; YAMAMORI, M.; HIRANO, H. and HIDAKA, S. Decrease of waxy (Wx) protein in two common wheat cultivars with low amylose content. Plant Breeding, September 1993b, vol. 111, no. 2, p. 99-105.

RODRÍGUEZ-QUIJANO, M.; NIETO-TALADRIZ, M.T. and CARRILLO, J.M. Polymorphism of waxy proteins in Iberian hexaploid wheats. Plant Breeding, September 1998, vol. 117, no. 4, p. 341-344.

ROZEN, S. and SKALETSKY, H.J. Primer3 on the www for general users and for biologist programmers. In: KRAWETZ, S. and MISENER, S. eds. Bioinformatics Methods and Protocols: Methods in Molecular Biology. Humana Press, Totowa, NJ, USA. 2000, vol. 132, p. 365386.

SAITO, M.; KONDA, P.; VRINTEN, P.; NAKAMURA, K. and NAKAMURA, T. Molecular comparison of waxy alleles in common wheat and identification o a unique null allele. Theoretical and Applied Genetics, May 2004, vol. 108, no. 7, p. 1205-1211.

SHARIFLOU, $M$. and SHARP, P. A polymorphic microsatellite in the 3 ' end of the 'waxy' genes of wheat, Triticum aestivum. Plant Breeding, July 1999, vol. 118, no. 3, p. 275-277.

URBANO, M.; MARGIOTTA, B.; COLAPRICO, G. and LAFIANDRA, D. Waxy proteins in diploid, tetraploid and hexaploid wheats. Plant Breeding, December 2002, vol. 121, no. 6, p. 465-469.

VRINTEN, P.; NAKAMURA, T. and YAMAMORI, M. Molecular characterization of waxy mutations in wheat. Molecular General Genetics, April 1999, vol. 261, no. 3, p. 463-471.

WICKRAMASINGHE, H.A.M. and MIURA, H. Gene dosage effect of the wheat $W x$ alleles and their interaction on amylose synthesis in the endosperm. Euphytica, July 2003, vol. 132, no. 3, p. 303-310.

WEINING, S. and LANGRIDGE, P. Identification and mapping of polymorphism in cereals based on polymerase chain reaction. Theoretical and Applied Genetics, August 1991, vol. 82, no. 2, p. 209-216. 
YAMAMORI, M.; NAKAMURA, T.; ENDO, T.R. and NAGAMINE, T. Waxy protein deficiency and chromosomal location of coding genes in common wheat. Theoretical and Applied Genetics, October 1994, vol. 89, no. 2-3, p. 179-184.

YAMAMORI, M.; NAKAMURA, T. and NAGAMINE, T. Polymorphism of two waxy proteins in the emmer group of tetraploid wheat, Triticum dicoccoides, T. dicoccum and $T$. durum. Plant Breeding, June 1995, vol. 114, no. 3, p. 215218.

YAMAMORI, M. and QUYNH, N.T. Differential effects of $W x-A 1-B 1$ and $-D 1$ protein deficiencies on apparent amylose content and starch pasting properties in common wheat. Theoretical and Applied Genetics, January 2000, vol. 100, no. 1, p. 21-27. 